\title{
BREVES REFLEXIONES SOBRE LOS PROBLEMAS DE LA TRADUCCIÓN EN JACQUES LACAN
}

\section{BRIEF REFLECTIONS ON THE PROBLEMS OF TRANSLATION IN JACQUES LACAN}

\section{Manuel Asensi Pérez \\ Universitat de València-Estudi General}

\section{ABSTRACT}

Translation is an essential dimensión in Lacan's work. It combines the difficulty of translating his mannerist style into other languages, and the practice of translation carried out by Lacan himself, especially in relation to Freud, but also in relation to other authors such Poe, Sophocles, Plato, Joyce, and a long etcetera. In this work, three concepts that have great importance within Lacanian theory have been taken as a point of reference: unterdrückt, verdrängt and Vervverfung. One of the theses that maintained throughout the following pages is that the relationship between unterdrückt and verdrängt it is not only a lexical or semantic problema, but that translation is present as one of the constitutive elements of the unconscious. Hence the importance of that topic. On the other hand, the term Verwerfung posed two types of problems: one for Lacan when he assimilated freudian texts, and another for the Spanish (or English, etc) translators of the same term.

Key words: Psychoanalysis, Lacan, Theory of Translation, unconscious, repression, forclusion. 


\section{RESUMEN}

La traducción es una dimensión esencial en la obra de Lacan. En ella se conjugan la dificultad de traducir a otras lenguas su estilo manierista, y la práctica de la traducción llevada a cabo por el propio Lacan especialmente en relación a Freud, pero también respecto a otros autores como Poe, Sófocles, Platón, Joyce, y un largo etcétera. En este trabajo se ha tomado como punto de referencia tres conceptos que tienen una gran trascendencia dentro de la teoría lacaniana: unterdrückt, verdrängt y Verwerfung. Una de las tesis que se sostienen a lo largo de las páginas que siguen es que en la relación entre unterdrückt y verdrängt no solo se trata de un problema léxico o semántico, sino que la traducción está presente como uno de los elementos constitutivos del inconsciente. De ahí la importancia de ese tema. Por otro lado, el término Verwerfung planteó dos tipos de problemas: uno al propio Lacan cuando asimiló los textos freudianos, y otro a los traductores al español (o al inglés, etc.) de ese mismo término.

Palabras clave: Psicoanálisis, Lacan, Teoría de la traducción, inconsciente, represión, forclusión.

Fecha de recepción: 5 de noviembre de 2021.

Fecha de aceptación: 9 de diciembre de 2021.

Cómo citar: Asensi Pérez, Manuel (2021): «Breves reflexiones sobre los problemas de la traducción en Jacques Lacan», en Actio Nova: Revista de Teoría de la Literatura y Literatura Comparada, monográfico 5: 56-72.

DOI: https://doi.org/10.15366/actionova2021.m5.003 
El propósito de este trabajo es analizar algunos problemas de traducción a que ha dado lugar la «obra» de Jacques Lacan (1901-1981). Esos problemas de traducción son del todo semejantes a los que se plantean cuando de traducir «literatura» se trata, incluido el vínculo de cierta literatura con la oralidad. ¿Cómo justificar la inclusión de un texto sobre Lacan dentro de un número dedicado a la relación entre literatura y traducción? A lo que podríamos responder: ¿Cómo se nos ocurre hablar de traducción sin hacer alusión al campo del psicoanálisis lacaniano?

Se recordará que la teoría de los polisistemas introdujo unos conceptos fundamentales para comprender la dinámica de los sistemas culturales: las intra- e interrelaciones. A nuestros efectos da lo mismo que se trate uno de una relación intrasistémica, y el otro de una extrasistémica. Zohar escribe: «cualquier sistema (poli)sistema semiótico (como la lengua o la literatura) no es más que un componente de un (poli)sistema mayor -el de la «cultura», al que está subordinado y con el que es isomórfico-y está correlacionado, por tanto, con este todo mayor y sus otros componentes» (1999: 15).

Naturalmente el fenómeno de la traducción, en sentido estrecho, juega un papel determinante en lo que son las relaciones extrasistémicas. Refiriéndose a los intercambios mutuos entre diferentes sistemas culturales, Zohar apunta: «Esto se ha demostrado en el caso de diferentes estratos que funcionan en buena medida en la periferia, tales como la literatura traducida» (15). Y menciona las obras de Toury, Shavit y Shavit, Yahalom, etc. No vamos ahora a señalar la importancia que ha tenido por ejemplo Gideon Toury en lo que a las teorías traductológicas se refiere, así como lo que denominó Descriptive Translation Studies (1995). Dicho de una forma sucinta: la traducción contempla los fenómenos de incorporación de sistemas semióticos de una lengua a los sistemas de otra lengua.

Una ojeada superficial a la obra de Lacan toma inmediata conciencia del papel que en su obra jugó Allan Poe, Sófocles, Gide o Joyce, entre otros muchos. ¿Qué encontró en el cuento de Poe «La carta robada»? ¿O qué encontró en los textos de Joyce? Es una temeridad dar respuesta a estas preguntas en este espacio tan breve, habida cuenta de las discusiones a que dio lugar su texto sobre «La carta robada», o su seminario sobre Joyce. Siempre me ha parecido extraña la crítica que Derrida (2001) lanzó contra el primer texto mencionado, especialmente porque revela una precipitación ciega que en alguien que propugnaba el close reading puede parecer extraño y desmedido. Más aún si tenemos en cuenta lo que el propio 
Derrida hizo con Rousseau, según la implacable demostración de Paul de Man (1983: 102141).

No vale la pena detenerse en esa idea derridiana según la que Lacan echa una mirada ciega al texto de Poe, habría en todo caso que dedicarle una atención en otro escenario. Las preguntas que sí contestaremos en este trabajo son estas: ¿cuál es el papel de la traducción en la obra de Lacan? ¿Qué papel juega o puede jugar la traducción en el pensamiento lacaniano? Y también: ¿qué es lo que la «literatura» le la da a Lacan? ¿En qué términos la traduce? (estas dos últimas preguntas serán respondidas en otro lugar). Pero para responder estas cuestiones será necesario hacer un recorrido en el que se dará la impresión de estar alejándonos de nuestro cometido, aunque pronto se descubrirá que no es así.

¿Cuál es el objeto de estudio del psicoanálisis? Para no complicar mucho las cosas digamos que ese objeto es el inconsciente y su forma de determinar la conciencia. Freud escribió en 1915 unas palabras que siguen siendo válidas:

El supuesto de lo inconsciente es necesario y legítimo (...) poseemos numerosas pruebas a favor de la existencia de lo inconsciente (...) Es necesario porque los datos de la conciencia son en alto grado lagunosos (...) Es, además, totalmente legítimo, puesto que para establecerlo no nos apartamos un solo paso de nuestro modo habitual de pensamiento (Freud, 2012: 163-165).

Más allá de la forma en que se explica la génesis del inconsciente a partir de la prohibición del incesto, y más allá de todas las teselas necesarias para construir la historia del sujeto, digamos que para Lacan el inconsciente no está formado por «ideas» como muchas veces reconoció Freud, sino por significantes carentes de significado. Lo que se retienen son huellas fonemáticas, letras. Solo con la llegada a la conciencia, de forma solapada, indirecta y deformadora, el significante adquiere un efecto de sentido. Lo primero que hay que decir es que estas afirmaciones no son claras, fáciles de describir, constituyen únicamente la punta del iceberg de todo lo que debajo se oculta.

Llegamos en este momento a un punto clave para nuestros intereses en este texto. ¿Cómo funciona el inconsciente? Si este no es una masa amorfa o un conjunto de ideas, en ese caso forma una cadena significante en movimiento sometida a las leyes de la metonimia y de la metáfora. Decir «ternera» en vez de «ternura» en un contexto en el que todo apoya la aparición del segundo significante, y no saber por qué demonios ha aparecido la ternerita por ahí, es un ejemplo de un movimiento del significante. Si se tiene en cuenta el desplazamiento continuo de la cadena significante, entenderemos por qué se habla de metonimia. Y si 
tenemos en cuenta los saltos que puede haber en ese desliz continuo, salta a la vista la estructura de la metáfora. A esa deriva del pensamiento por descubrir la estructura del inconsciente, se suma el hecho de que el eje del inconsciente no puede descansar en un «yo» psicológico (al que Lacan denomina moi), si quiera por el hecho de que no puede controlar, ni se entera, de los movimientos de ese inconsciente. No puede sino descansar en un entidad puramente gramatical y deíctica (para la que Lacan reserva el pronombre je), sin ningún atisbo de rasgos humanos o psicológicos.

Fue justamente en el seminario donde Lacan trata con todo detalle la formación del inconsciente donde habló de su propio estilo, de su forma de expresarse. Es un momento en el que remite a los oyentes a su trabajo «La instancia de la letra» (1966: 493-530), y dice lo siguiente:

$\mathrm{Al}$ parecer, al algunos, lo que les impide entrar en ese artículo es, digamos mi estilo. Lo siento, no puedo hacer nada al respecto - mi estilo es lo que es. Les pido que hagan un esfuerzo. Tan sólo añadiré que cualesquiera que sean las deficiencias que puedan intervenir debidas a mí personalmente, hay también en las dificultades de este estilo — quizá puedan entreverlo — algo que responde al propio objeto en cuestión (Lacan, 1999: 32).

No se crea que Lacan deja en suspenso esa cuestión, bien al contrario, lo explica de inmediato.

¿Cuál es el objetivo de ese seminario? El planteamiento no es claro, sin duda, pero el objetivo parcial sí: hablar de las funciones creadoras del significante, en dos direcciones, en lo que se refiere a la dinámica del inconsciente, y en lo que toca al campo de la realidad. Como resulta que, por tanto, se trata de hablar de la palabra siguiendo el hilo de la palabra (estoy parafraseando lo que Lacan dice) ¿no sería una inconsecuencia usar el significante en contra de sí mismo? Y sí, el estilo de Lacan es calificado por él mismo de «manierista», y de manierismo en la filología hispánica sabemos mucho.

Ese manierismo no afecta solo a los movimientos en el seno de la lengua francesa. A fin de cuentas, la distinción entre el «je» y el «moi» no es propiamente algo que un hablante francés pueda encontrar en los usos de su lengua, sino que forma parte de lo que podríamos llamar la «creatividad lingüística» de Lacan. Pero todo no acaba ahí. Se trata también de atravesar el francés para irse al alemán, por ejemplo, el de los textos de Freud: «Vean ustedes aquí, al mismo tiempo, la diferencia de matiz que podemos establecer entre lo unterdrückt, por una parte, y lo verdrängt, por otra parte» (Lacan, 1999: 43). ¿Por qué mantener esos términos 
tan importantes del discurso freudiano en alemán? Justo por el hecho patente de la intraducibilidad. El grafo sobre el que Lacan está trabajando en ese seminario es el siguiente, un grafo destinado a ilustrar topológica y matemáticamente el mecanismo del Witr:

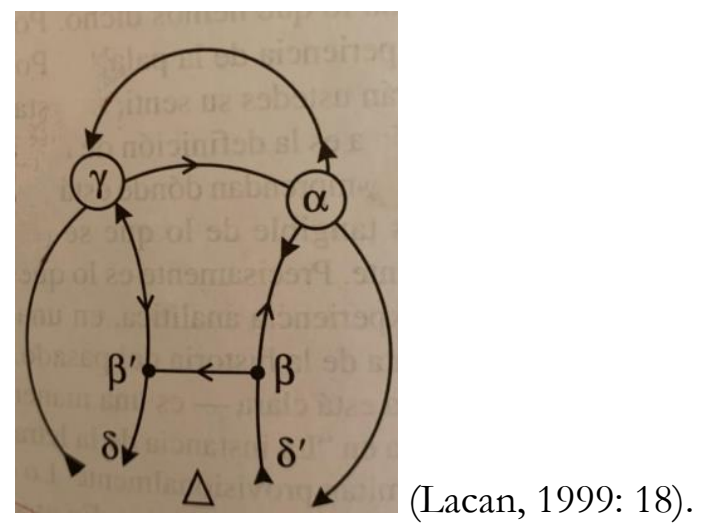

De entrada, la delta mayúscula viene a representar la necesidad de decir o de hacer algo. Mi voluntad quería poner de relieve el efecto de ternura que se desprendía de aquel pasaje de la poesía de un poeta español. Eso es lo que yo quería decir, era mi Bedeutung. Pero en el camino hacia el código (alfa minúscula), el inconsciente me sorprendió (la beta, el je al que nos hemos referido), y creo un desplazamiento (beta prima) que dio lugar a que en vez de «ternura» yo dijera «ternera». En la gamma se disputaron el lugar «ternura» y «ternera», y alcanzó el éxito (o el desastre) la segunda palabra.

Eso sucede porque en el código (en el punto alfa) esas dos posibilidades existen como dadas de antemano. Lacan no habla de ese caso, como es obvio, sino del olvido propio narrado por Freud en su obra Psicopatología de la vida cotidiana (1901). No conseguía recordar el nombre (Signorelli) del autor de los frescos que había contemplado en la catedral de Orvieto. En vez de ello las palabras que acudían a su memoria eran Boltraffio y Botticelli. Digámoslo en los términos que interesan a este ensayo: Signorelli había sido traducido como Boltraffio y Botticelli.

¿Cuál es la forma en la que la conciencia traduce el inconsciente? De una manera totalmente deformada. Por mucho que «ternura» y «ternera» contengan prácticamente los mismos fonemas y solo varíe una vocal, son términos muy alejados en nuestra percepción. Algo semejante ocurre con la relación entre Signorelli y la pareja Botticelli-Boltraffio. ¿Qué justifica esa transformación? El pavor de Freud ante la muerte y, por extensión, la falta de potencia sexual. Lacan apunta: «¿Quién está detrás de todo esto? El Herr absoluto, la muerte. 
La palabra se larga a otra parte, se borra, recula, repelida, es unterdrückt, hablando con propiedad». Y Lacan apunta: «Hay dos palabras con las que Freud juega de forma ambigua. La primera es este unterdrückt, que ya les he traducido como caído en las interioridades (tombé dans les dessous). La segunda es verdrängt» (Lacan, 1999: 41).

Detengámonos un momento, porque aquí estamos englobando tres fenómenos diferentes: uno tiene que ver con la traducción entre el inconsciente y el consciente, a partir del hecho de que en el punto de partida no hay sentido; el otro tiene que ver con la vigilancia del sentido que tienen los términos en un texto de partida (el de Freud), y que en el texto de llegada no pueden tener equivalencia, ni semántica ni funcional; el tercero afecta a la inevitable porosidad del lenguaje de Lacan, porque ¿cómo podría ser claro lo que está sometido al vaivén de la metonimia y de la metáfora? Lo cual da razón de ser de lo que él mismo denomina lenguaje manierista. Por cierto, este último aspecto lleva a otra dimensión del problema: traducir a Lacan.

De hecho, ese «tombé dans les dessous» que hemos puesto entre paréntesis es, en realidad, una nota al pie de página del traductor de ese seminario, Enric Berenguer. Este avisa de que esa expresión «significa «los intríngulis», lo que está debajo, y designa la ropa interior femenina [N. Del T.] «(Lacan, 1999: 41, nota 7). ¿Por qué esa nota? Porque si no se pone ese aviso, el lector no percibirá el haz de sentidos que abre el texto francés. Como puede observarse, el campo del psicoanálisis lacaniano es el de la traducción. Si este fenómeno mueve el lenguaje, la dinámica de la metonimia y de la metáfora, también afecta a las palabras que empleamos para hablar de ello en una falsa posición metalingüística. De hecho, podría decirse que estamos tocando el problema esencial de toda traducción.

$\mathrm{Al}$ decir que Freud emplea de forma ambigua los términos unterdrückt y verdrängt nos está diciendo que resulta imposible traducir esos términos, de ahí que los mantenga en su recorrido en alemán. Toda esta problemática en torno a esas dos expresiones viene suscitada por el caso que Freud tiene sobre su lupa. Todas las iras han recaído sobre el término «Signor», no hay manera de que acuda a la mente de esa persona. Expliquémoslo con cierto detenimiento para que entendamos la vigilancia que Lacan propone respecto a esos dos términos. ¿Cómo se dice «Signor» en alemán? Herr es su equivalente. Pero he aquí que en la conversación que hacía un tiempo Freud había mantenido con un colega y, después, con el familiar de un enfermo, se habían pronunciado dos frases: «Herr [señor], no hay nada más que decir. ¡Yo sé que si se lo pudieras salvar, lo habrías salvado» (la primera); y «Sabes tú, Herr, cuando eso ya no ande, la vida perderá todo valor». 
El propio Freud nos indica cómo el término «Herr» ha adquirido desde ese momento un haz de sentidos vinculados al tema reprimido. En una dirección, ha suscitado la idea de la muerte (primera frase). En otra ha evocado la idea de la pérdida de la potencia sexual (segunda idea). En el esquema que dibuja Freud en la página 12 de la edición de Amorrortu, se ve muy bien que en el proceso de intento de recuerdo en el elemento que se ha olvidado es la cadena formada por « (Signor)elli- (Her)zegovina- (Herr)». Lo que se deja de lado, lo que la mente se niega a decir es el vínculo entre «Signor-Her-Herr», y la mente no lo recupera porque lo que quiere marginar es la pareja formada por la «muerte-pérdida de potencia sexual».

¿Cuál es la relación entre «Signor»y «Herr»? La de una traducción interlingüística.

Oigamos a Lacan:

Si Signor no puede ser evocado, si él es la razón de que Freud no pueda dar con el nombre de Signorelli, es porque está implicado. Está implicado, evidentemente, de una forma indirecta, a través de Herr. Herr ha sido efectivamente pronunciado, en un momento particularmente significativo de la función que puede adquirir como Herr absoluto, en cuanto representante de la muerte que en esta ocasión está unterdrückt. El Signor solo está implicado en la medida en que puede traducir Herr. Aquí nos encontramos nuevamente en el nivel sustitutivo (Lacan, 1999: 42).

Este planteamiento resulta atractivo por cuanto descubrimos que un elemento puede estar unterdrückt no solo dentro de una lengua, sino en el cruce entre lenguas. Las huellas fónicas se establecen en el interior de una lengua, pero dado que son varias las lenguas con las que un sujeto se cruza en su vida, son huellas fónicas interlingüísticas.

Lacan llama la atención sobre el hecho de que para alguien que hable alemán no es lo mismo decir Signor que decir Herr. Y no es indiferente el hecho de que un paciente cuando tenga que decir algo en una lengua distinta a la suya lo diga, siempre hay un sentido en el hecho de expresar algo en una lengua determinada.

Sin embargo, no encontrar el Signor(elli) porque detrás está el Herr no sitúa en el mismo proceso a uno y a otro. $\mathrm{Y}$ es a este respecto que conviene hacer la diferencia entre lo que está unterdrückt y lo que está verdrängt. De hecho, el problema de Freud en cuanto a su imposibilidad de recordar no afectaba al Herr, sino al Signor (elli). Está claro que ha habido una sustitución, como en toda traducción, que Lacan denomina «heterónima». Obsérvese que Freud es muy claro a este respecto: Lo recuerdo bien; quería yo contar una segunda anécdota que en mi memoria descansaba próxima a la primera» (Freud, 1980: 11). En esa anécdota a la que se refiere, ya lo hemos visto, estaba presente el Herr: «Sabes tú, Herr, cuando 
eso ya no ande...». E insiste en que lo olvidado es el nombre del maestro de la catedral de Orvieto, Signorelli. En este relato se pone de manifiesto que el olvido del Signor vino a causa de su conexión con el Herr y los significantes ahí implicados. Cuando Lacan afirma que se trata de una traducción heterónima se refiere al hecho de que «Signor» $\mathrm{y}$ «Herr» tienen una gran proximidad semántica pero una forma diferente en sus respectivas lenguas. Insistamos: es lo que ocurre en el ideal de toda traducción (Nida y Taber, 1986).

Entonces, ¿cuál ha sido el proceso que se ha seguido ahí? Lacan dice: «Si lo unterdrückt sólo necesita tener lugar de una vez por todas y en condiciones a las que el ser no puede descender en su condición mortal, se trata de algo distinto cuando Signor es mantenido en el circuito sin poder volver a entrar durante algún tiempo» (Lacan, 1999: 43). El circuito al que se está refiriendo es el que hemos expuesto antes. Por cierto, al nombrar dicho circuito aparece otro problema vinculado a los problemas de la traducción. Las citas que de Lacan estamos aportando pertenecen a una traducción de la versión oficial preparada por JacquesAlain Miller en Seuil (1998). El traductor fue Enric Berenguer, a quien hay que alabar por su trabajo. Pero he aquí que la versión preparada en francés por Jacques-Alain Miller es, a su vez, una traducción intralingüística (Jakobson (1958)) basada en las copias que se hicieron del discurso oral de Lacan. Así, por ejemplo, en la edición de Staferla, nos encontramos ante un texto más clarificador. En principio, porque la mención del circuito va acompañada por una reproducción del grafo que en la edición de Miller solo se expone una vez. En cambio, Lacan está constantemente mostrándolo. En esta ocasión tenemos este «circuito» que él da a ver:

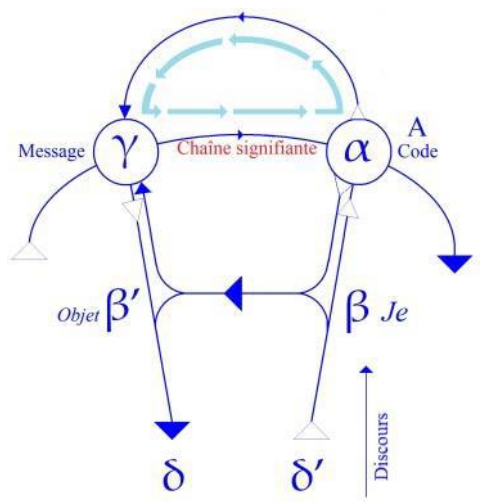

(Lacan, 1957-58: 19).

A diferencia del que aparece en el texto oficial de Seuil, aquí nos encontramos con una clarificación de los términos que ahí aparecen. La detractio realizada por Miller oscurece 
más el texto, lo deja más abierto, hace que el significante flote más. Ahí en ese grafo se aclara que la letra alfa se refiere al Código, la gamma al mensaje, la beta al sujeto del inconsciente, la beta prima al objeto metonímico (al movimiento del significante), las letras delta aluden a la dimensión diacrónica del lenguaje, y la línea que va de izquierda a derecha que cruza el mensaje y el código aparece nombrado como «cadena significante». A ello se añaden dos factores más: el término «discurso» y las fechas verdes del piso de arriba que indican la ida y vuelta entre el mensaje y el código. Si Lacan lo nombra como Discours es porque el caso que están tratando es el del olvido de un nombre, aunque una afonía (como en el caso de Dora) es también un discurso. Por último, digamos que el empleo de los colores (azul, rojo y verde) no es gratuito, como veremos enseguida.

Volvamos un momento al texto de Freud para recuperar una afirmación suya que nos ayudará a dirigirnos por el camino adecuado. He aquí sus palabras (en una traducción, claro): «Este olvido de nombre sólo se explica al recordar yo el tema inmediatamente anterior a aquella plática, y se da a conocer como una perturbación del nuevo tema que emergía por el precedente» (Freud, 1980: 10). Freud señala dos momentos diferentes: en primer lugar, estuvo la conversación referida a las costumbres de los turcos y la respuesta que suelen dar ante la proximidad de la muerte en presencia del médico (donde aparece el primer Herr «Herr, no hay nada más que decir...»). Tras ello (en el orden cronológico enumerado por Freud) vino el momento en que preguntó a su compañero de viaje si había estado en Orvieto y visto los frescos de X. ¿Qué marca la X? Ya lo sabemos, el olvido del nombre de Signorelli. Y reconoce, además, que «quise olvidar algo, había reprimido algo. Es verdad que yo quería olvidar otra cosa que el nombre del maestro de Orvieto, pero esto otro consiguió ponerse en conexión asociativa con su nombre, de suerte que mi acto de voluntad erró la meta, y yo olvidé lo uno contra mi voluntad cuando quería olvidar lo otro adredes (Freud, 1980: 11-12). Estos dos movimientos no pueden subsumirse en un solo concepto, y por eso dice Lacan que «si Herr se ha largado por aquí, hacia las $\beta$, el Signor, como lo indica la dirección de las flechas, se ha largado hacia $\alpha-\gamma \gg$ (Lacan 1999: 43).

Podría parecer que nos encontramos ante un simple fenómeno de olvido, pero al leer cuidadosamente los textos de Freud y de Lacan nos damos cuenta de que no es así. Si miramos el grafo anterior veremos que mientras el Herr se sitúa en el eje del je $(\beta)$ y el objeto metonímico $\left(\beta^{\prime}\right)$, el Signor se mueve en el piso de arriba entre el mensaje $(\gamma)$ y el código $(\alpha)$. ¿Qué es lo que quería olvidar Freud adrede? El Herr y sus implicaciones en lo referido a la muerte y a la pérdida de potencia sexual. 
¿Y qué es lo que no quería olvidar? El Signor presente en Signorelli, de forma la conversación allí en el tren fuera fluida. Sin embargo, justo el Signorelli fue olvidado. Cuando Lacan dice que hay una diferencia de matiz entre lo unterdrückt y lo verdrängt, comenzamos a comprender la razón de ello. El comentario según el que «el Signor es mantenido en el circuito sin poder volver a entrar durante algún tiempo» (Lacan 1999: 43) quiere decir que ese término se halla en ese movimiento indicado por las flechas verdes que realizan el movimiento de ida vuelta entre el código y el mensaje. Esta vigilancia del sentido de los dos términos alemanes arroja como resultado que el Signor ha sufrido una verdrängt, una represión en el circuito que va del mensaje al código y viceversa, mientras el Herr, dice Lacan, está unterdrückt en el nivel del discurso.

¿Para qué sirve esta distinción de una atención francesa sobre un texto alemán? Para comprender de la forma más profunda el proceso de un olvido y, por extensión, de toda patología. Lo que está unterdrückt (oprimido, sometido, contenido, disimulado, haz de sentidos a que da lugar este término) determina lo que está verdrängt (reprimido). Si la intención de decir algo en una situación de emisión de un discurso se puede ver truncada por una posición inconsciente, el pavor al Herr y sus implicaciones, el resultado es que algo desaparece en el mensaje, esto es en la circulación entre mensaje y código. ¿Qué hacemos cuando algo se nos olvida? Intentamos dar con ello, es como si buscáramos en una caja (el código) algo que no se encuentra por ningún lugar y por tanto desparece del mensaje. Esa posición inconsciente es lo que en el grafo aparece marcado como $\beta$ y $\beta$, el Herr absoluto que marca el desplazamiento metonímico y metafórico que ocasiona una desaparición en la cadena significante que oscila entre el mensaje y el código. Ahora ya podemos decirlo: del nivel combinatorio (metonímico) propio de la $\beta$ ' pasamos al nivel sustitutivo en el que se produce la sustitución de Herr por Signor con la consiguiente caída de este. Ha sido, pues, la traducción la que, como efecto, ha dado lugar a un olvido. Puede parecer extraño que una traducción se vea implicada en un olvido, pero entiéndase que es esa conexión la que le impidió a Freud dar con el nombre que buscaba.

En el texto de Staferla, aquel en el que se recoge la oralidad del discurso de Lacan, este repite una y otra vez el circuito de colores para que la audiencia pueda consultarlo sin desorientarse. Tras mencionar la necesidad de distinguir los dos niveles, el nivel combinatorio, donde se produce el objeto metonímico, y el nivel sustitutivo, donde se produce la metáfora Herr-Signor y el mensaje faltante, el texto de la versión oficial dice: «Signor está reprimido, verdrängt, en el circuito mensaje-código, mientras que Herr está unterdrückt en 
el nivel del discurso, y lo que les pone a ustedes tras las huellas del significante perdido son las ruinas metonímicas del objeto» (Lacan 1999: 44-45). El texto francés de la transcripción dice, sin embargo:

Nous l'avons vu, le "SIGNOR" est refoulé ici dans le circuit message-code $[\gamma-$ $\alpha]$, le "HERR" est unterdrückt a niveau du discours, car c'est le discours qui a précedé, qui a capté ce "Herr", et ce que vous retrouvez, ce qui vos permet de vous remettre sur les traces du significant perdu, ce sont les ruines métonymiques de l'objet (24).

No solo cambia la estructura sintáctica, pues en el texto de Staferla la frase que se inicia con «le SIGNOR» es un objeto directo de verbo «ven», mientras que en la versión oficial es una nueva frase que se introduce después de un punto.

Esta diferencia en cuanto al point de capiton, aumenta cuando se advierte que el juego de los énfasis es mayor en el texto de Staferla que en la versión oficial: de hecho, la frase «las ruinas metonímicas del objeto» aparecen sin un valor enfático en esta última, mientras que en la primera están enfatizadas con cursiva y con un color azul, semejante al del grafo. Por último, en esa misma versión, tras la frase «les ruines métonymiques de l'objet» el oyente o el lector se encuentras de nuevo ante el grafo que se ha expuesto un poco más arriba. Una rápida ojeada a ese grafo clarifica a que se está refiriendo Lacan cuando habla de esas ruinas metonímicas del objeto: si en vez de expresar Signorelli se dice Botticelli o Boltraffio, ¿qué queda de aquella palabra cuando la metonimia ha creado un desplazamiento sino un resto en Botticelli? ¿Cuál? «elli». Es esa $\beta$ ’ lo que ha cercenado la palabra Signorelli y ha hecho que llegue hasta el mensaje en su forma desfigurada actual. Puede verse que en el grafo hay dos líneas que confluyen sobre la $\gamma$, una que representa el querer decir del sujeto, la superior, y otra que proviene de la parte de abajo, desde la $\beta$ '.

Hasta aquí hemos examinado los problemas relacionados con la traducción que presenta el corpus de la obra lacaniana, y hemos podido comprobar la complejidad que reviste solo analizando el ejemplo de la diferencia entre lo que se halla unterdrückt y lo que permanece verdrängt. Ahí ha quedado claro que la traducción atraviesa de punta a punta toda la obra de Lacan debido a diferentes causas que hemos ido señalando. Pero esto mismo que hemos ido estudiando a propósito de la relación entre Lacan y Freud, puede ser relacionado con el problema que representan no Freud, sino Joyce, Poe, Shakespeare o Sófocles, entre otros. 
Posiblemente necesitaríamos una enciclopedia para responder por separado a esas relaciones, y de hecho Lacan dedicó en 1975-76 todo un seminario a Joyce. La razón de la amplitud de dichos temas es lo que nos impide afrontarlo con cierta solvencia en este lugar. En consecuencia, en lo que sigue vamos a introducir un tercer elemento junto a unterdrückt y verdrängt. Se trata del concepto de Ververfung, que dio lugar a otro fenómeno de traducción. No se puede hablar solo del seminario 23, el que dedica a Joyce, sin hacer referencia al número 3 que dedicó al fenómeno de la psicosis (1955-56), y aún en otro sentido al ensayo incluido en los Escritos, titulado «De una cuestión preliminar a todo tratamiento posible de las psicosis» (1966: 531-584).

De entre los procesos que escapan a la conciencia ya hemos visto que unterdrückt se refiere a una omisión provocada por un movimiento metonímico, mientras que verdrängt nombra la represión misma provocada en el nivel del código y del mensaje. Pues cabo otra posibilidad y esta consiste en el que en la resolución edípica la función del nombre-del-padre no cumpla su cometido. En ese caso, se produce un agujero no en la cadena significante consciente, sino en la cadena significante inconsciente. En el grafo anterior ha quedado representada la mecánica del inconsciente, y Freud, como neurótico, como cualquier situación de la vida cotidiana, puede sufrir problemas de memoria. Sucede que podría ocurrir que algo no entrara en ese circuito formado por la $\beta$ y la $\beta$, la $\alpha$ y la $\gamma$. Cuando a causa de una negativa a la castración y la ausencia de la función del Nombre-del-padre, un significante esencial, cuya función es organizadora, no tiene lugar, entonces ya no hablamos de Verdrängung (represión), ni de Verdichtung (el malentendido), ni de Verneinung (la negación), sino de Verwerfung.

En este último fenómeno lo reprimido no se integra en la cadena significante inconsciente, sino que queda arrojado a lo real, y vuelve al sujeto bajo la forma de una alucinación que el sujeto toma por verdadera. Es a eso a lo que se denomina Verwerfung: "En la relación del sujeto con el símbolo, existe la posibilidad de una Verwerfung primitiva, a saber, que algo no sea simbolizado, que se manifieste en lo real" (Lacan, 2015: 119).

En torno a este término se plantean numerosos problemas de traducción. Uno tiene que ver con la forma de traducir en francés o en español ese término. Si nos fijamos en el texto francés de Lacan, el aparecido en los Escritos, tenemos lo siguiente:

Extrayons de plusieurs textes de Freud un terme qui y est assez articulé pour les rendre injustifiables si ce terme n'y désigne pas une fonction de l'inconscient 
distincte du refoulé. Tenons pour démontré ce quif ut le coeur de mon 'séminaire sur les psychoses, à savoir que ce terme se rapporte à l'implication la plus nécessaire de sa pensé quand elle se mesure au phénomène de la psychose; c'est le terme Verwerfung. (Lacan 1966: 558).

En su trabajo «De la historia de una neurosis infantil», Freud había reconocido que «una represión (Verdrängung) es algo diferente de una desestimación (Verwerfung)» (Freud, 2003: 74). Y un poco más adelante hablando de la actitud del niño ante la amenaza de castración anotaba: «Nos ha venido notoria la inicial toma de posesión de nuestro paciente frente al problema de la castración. La desestimó y se atuvo al punto de vista...» (Freud, 2003: 78). Tiene razón Lacan cuando subraya en Freud la diferencia entre la Verdrängung y la Verwerfung, y en que podían dar lugar a una diferencia entre la neurosis y la psicosis. ¿Cómo ha traducido el último término José L. Etcheverry? Ya lo acabamos de ver, como «desestimación». Sin embargo, la traducción de Tomás Segovia, recientemente revisada por Juan David Nasio y Armando Suárez habla de «preclusión». Es cierto que tanto forclusion en francés como preclusión en español pertenecen de entrada al léxico procesal y tienen el significado mencionado antes.

El propio Lacan, en el seminario 3 sobre las psicosis, dice en un momento determinado esto: «No retorno a la noción de Verwerfung de la que partí, y para la cual, luego de haberlo reflexionado bien, les propongo adoptar definitivamente esta traducción que creo la mejor: la forclusión» (Lacan, 2015: 456). Y está en lo cierto porque a lo largo de todo el seminario, cuando menciona ese proceso, emplea el término alemán freudiano. Es en la sesión del 4 de julio de 1956 cuando sugiere que la traducción del Ververfung quede como forclusión. Los traductores, Juan-Luis Delmont-Mauri y Diana Silvia Rabinovich son los que llamaron la atención en nota al pie de página sobre los sentidos que la palabra tiene en francés y sobre el hecho mencionado anteriormente de que el Petit Robert incluye la acepción psicoanalítica.

En conclusión, al final, en la literatura psicoanalítica se ha impuesto la presencia del término forclusión. Mientras en francés hemos visto un desplazamiento de sentido que ya aparece en los diccionarios franceses, en español se ha optado por crear un neologismo, un término que ha tenido que inventarse cuando previamente no existía. De algún modo, los traductores españoles han reconocido la intraducibilidad de ese término y, por ello, han decidido dejarlo en francés adaptado al español. 


\section{BIBLIOGRAFÍA}

Alain-Miller, Jacques (1999): El establecimiento de «El Seminario» de Lacan, Buenos Aires, Tres Haches.

De Man, Paul (1983): Blindness and Insight. Essays in the Rhetoric of Contemporary Criticism, Minneapolis, University of Minnesota Press.

Derrida, Jacques (2001): La tarjeta postal. De Sócrates a Frendy más allá. México, Siglo XXI.

Even-Zohar, Itamar (1999): «Polisistemas de cultura», en Martínez, Monserrat (1999), Teoría de los polisistemas, Madrid, Arco Libros: 71-96.

Freud, Sigmund (1980): Obras completas. Volumen 6. Psicopatología de la vida cotidiana (1901), Buenos Aires, Amorrortu.

Freud, Sigmund (2003): Obras completas. Volumen 17. De la historia de una neurosis infantil (el «Hombre de los Lobos») y otras obras (1917-1919), Buenos Aires, Amorrortu.

Freud, Sigmund (2012): Obras completas. Volumen 14. Contribución a la historia del movimiento psicoanalitico. Trabajos sobre metapsicología y otras obras (1914-1916), Buenos Aires, Amorrortu.

Lacan, Jacques (1955-56): Les psychoses, Paris, Staferla.

Lacan, Jacques (1957-58): Les formations de l'inconscient, Paris, Staferla

Lacan, Jacques (1966): Écrits. Paris, Seuil. Traducción al español de Tomás Segovia (1971), Escritos 1 y 2. México, Siglo XXI. Edición revisada por Juan David Nasio y Armando Suárez (2009), Escritos 1 y 2. México, Siglo XXI.

Lacan, Jacques (1999): El seminario de Jacques Lacan. Libro 5. Las formaciones del inconsciente, Buenos Aires, Paidós. Traducción al español de Enric Berenguer.

Lacan, Jacques (2015): El seminario de Jacques Lacan. Libro 3. Las psicosis, Buenos Aires, Paidós. Traducción al español de Juan-Luis Delmont-Mauri y Diana Silvia Rebinovich.

Mesdchnnic, Henri (1973). Por la poétique: épistemologie de l'écriture poétqie de la traduction, Paris, Gallimard.

Neubert, A. y Shreve, G. M. (1992): Translation as Text, Kent-Ohio-London, The Kent State University.

Tizio Domínguez, Hebe M. (1990): Psicoanálisisy lenguaje. La aportación original de Jacques Lacan, Tesis doctoral presentada en la Universidad de Barcelona.

Toury Gideon (1995): Descriptive Translation Studies and beyond, Amsterdam/Philadelphia, Johns Benjamins Publishing Company. Traducción al español y edición de Raquel 
Merino-Álvarez y Rosa Rabadán: Toury, Gideon (2004): Los estudios descriptivos de traducción y más allá. Metodología de la investigación en estudios de traducción, Madrid, Cátedra. 


\section{SOBRE EL AUTOR}

\section{Manuel Asensi Pérez}

Manuel Asensi es Catedrático de Teoría de la Literatura y de la Literatura Comparada en la Universidad de Valencia. Psicoanalista. Entre 1992 y 1996 fue Visiting Professor en la Universidad de California (Irvine) en el Departamento de Español y Portugués, donde enseñó materias relacionadas con la teoría literaria, la literatura latinoamericana y el psicoanálisis. Ha sido, asimismo, profesor invitado en diferentes universidades norteamericanas, europeas y latinoamericanas. Es director del Grupo de Investigación «Crítica y sabotaje» que reúne a investigadores e investigadoras de distintas Universidades españolas y norteamericanas, y ha sido investigador principal de diferentes proyectos de investigación I+D. Ha fundado recientemente y dirige la Asociación Española de Psicoanálisis Lacaniano. Dirige, asimismo, el Diploma de Posgrado de la Universidad de Valencia «Literatura Comparada y Crítica Cultural». Fue director del Programa de Estudios Independientes del MACBA. Dirige la revista Prosopopeya. revista de crítica contemporánea. En la actualidad trabaja en dos proyectos: en una modalidad crítica denominada «crítica como sabotaje» o «Teoría de los modelos de mundo», y en la difusión del pensamiento lacaniano. Algunas de sus sesiones se pueden ver en Youtube, donde sus videos han alcanzado más de doscientas mil visualizaciones.

Contact information: Departamento de Teoría de los Lenguajes y Ciencias de la Comunicación, Facultad de Filología, Traducción y Comunicación. Ava Blasco Ibáñez, n. 10, Valencia 46010. Telf.: 963864264. E-mail: manuel.asensi@uv.es 